\title{
Nepalese context: Should physician treat themselves and their family members?
}

\section{Dhakal AK}

Ajaya Kumar Dhakal, Lecturer, Department of Paediatrics, KIST Medical College, Imadol, Lalitpur, Nepal.

\section{ABSTRACT}

Physicians are individuals with families and friends and it is their duty as well as moral and social obligation to look after their friends and relatives when they become sick. But what should be their role in looking after one's own sick family members or friends? As far as it is not as a treating physician there should be no problem but if physicians are to take responsibility of treating their family members as a physician, a number of ethical issues arise. Medical advice and medical treatment of family members is a subject of debate. The current codes of ethics of in many countries advise physicians not to treat their family members except in emergency situations and for minor illnesses. What should Nepalese physicians do?

Key words: Ethics, Physicians and family member, Self-medication

\section{INTRODUCTION}

$\mathrm{M}$ edical advice and treatment of own kid, spouse, parents and other family members by physician is common throughout the world ${ }^{1}$ and also prevalent in Nepal although studies regarding its incidence are scarce. The drugs prescribed for own family members range from paracetamol for fever, medication for simple allergies, or contraceptives to antibiotics for common infections ${ }^{2}$. Similarly self medication among physician is also a very common practice. Often, they treat themselves with psychiatric medication, sedative and hypnotics, antihypertensive, analgesics, antacids and antibiotic etc ${ }^{3}$. The history of treating family members began with development of medical science, but the issues associated with it are often neglected and never taught or discussed in any medical school or forums ${ }^{4}$. These issues need to be addressed as these are bound to result in short and long term consequences, least one of them could be jeopardizing doctor patient relationship.

These universally practiced and unaddressed issues discussed in this article are of significant interest as well as concern to many physicians in Nepal. This calls for intense discussions and debate among physicians

Address for correspondence

Dr. Ajaya Kumar Dhakal

Department of Paediatrics

KIST Medical College, Imadol, Lalitpur

E-mail: ajayakdhakal@gmail.com in order to clarify the issues and develop mechanisms in accordance with the universally accepted norms and standard which would address ethical, professional and social aspects of self-treatment and treatment of family members.

\section{DISCUSSION}

Medical professionals from all disciplines and specialties of medicine in Nepal face numerous questions from their immediate family members, relatives, friends and even neighbours about diseases, medications, diagnostic investigations and whether to undergo any procedure, in a variety of setting like family gatherings or through telephonic conversation. Such practices are prevalent throughout the world. A study conducted among physician in community teaching hospital in United Kingdom reported that almost all physicians interviewed reported getting a request for medical opinion or treatment from family members ${ }^{5}$. A physician's decision to treat and prescribe medications is followed by his/ her worries about diagnosis, course of disease, fear of complication which may create a sense of insecurity and anxiety in the physician that may interfere with the delivery of best option for treatment and care. Despite such challenges many physicians are found treating their family members primarily because of convenience in treatment ${ }^{6}$.

Majority of families in Nepal live in extended joint families where family members from different generations with 
different age group live together. In such families, a physician might be giving opinion to or treating a child with running nose and fever and elderly relative with prolonged cough simultaneously. Family bonding and family values are extremely strong in Nepalese society and a physician always face tremendous familial pressure of responsibility to treat even-though he/she may not be comfortable in treating his/her family members and relatives. Many times it may be a source of conflict in family when their expectations are not met. Moreover, at times it may be challenging to separate familial and professional roles when a family member is sick and ethical guidelines help little in these real life scenarios?.

The problem of treating family and close relative starts from initial history taking and extends beyond physical examination. Physicians may not be able to elicit full information through history and physical examination due to lack of privacy. Male physicians will be very reluctant to conduct examination of reproductive system of their female relatives and vice versa and thus will be handicapped in making a diagnosis and treatment plans. In addition, there may be problems of confidentiality and treatment compliance compromising quality of care provided by a physician ${ }^{8}$. The effect of incomplete information and examination along with emotional involvement while making decision while treating family members compromises rational management affecting optimal care of patients ultimately violating professional ethics ${ }^{9}$.

The physicians in Nepalese society are expected to provide guidance and assistance to various types of medical question of their family members and close relatives not only related to drug treatment but also about medical information. These are a few examples or types of questions faced by the physicians from their relatives: "Which is the best lab in Kathmandu?", "I am doing my sugar check in that lab, is that reliable?", "I was advised for that investigation, is that ok?", "Doctor said I have to undergo operation, can it be cured with drugs or can I undergo operation after six months?", "Is ayurvedic medication good for this disease?", "Who is the best physician in a particular field?", "I am having chhakar lagne (giddiness) do I have pressure (blood pressure problem)?", "I heard symptoms of blood sugar problem in television i also have same symptoms. Do I have diabetes?"

Similar was the experience of the physicians in the developed countries as well as reported by an earlier study which highlights the universal nature of the issue ${ }^{10}$. It is important to emphasize that these questions are asked on telephone without physical presence of the patient and the physician's inability to satisfactorily answer their questions is a potential source of disharmony between a physician and family members or relatives.

Despite critical concern and debate about physicians treating their own family members, a community survey involving 461 physicians in United Kingdom has found that about $83 \%$ percent of physicians prescribed medications for a family member, $80 \%$ diagnosed medical illnesses, $72 \%$ performed physical examinations, $15 \%$ acted as a family member's primary doctor and $9 \%$ performed surgery on a family member ${ }^{5}$. This study highlighted that such practices are widespread throughout the globe.

The ethical issues related to such delicate doctor patient relationship are addressed neither in undergraduate nor in post graduate courses in medical education in Nepal. Nepal Medical Council and Nepal Medical Association have a very important role in advising and educating physician about this aspect of doctor patient relationship.

The current code of ethics published by medical councils of several countries advise physicians to refrain from treating family members unless in emergency situations and for minor illness ${ }^{11},{ }^{12}$. The American Medical Association's code of ethics says "Physicians generally should not treat themselves or members of their immediate families. Professional objectivity may be compromised when an immediate family member or the physician is the patient"11. In similar context, Good Medical Practice guidelines from United Kingdom states: 'Wherever possible, you should avoid providing medical care to anyone with whom you have a close personal relationship ${ }^{\prime 2}$. Similar recommendations are echoed by Medical Council of Ireland, Canada and New Zealand ${ }^{12}$.

\section{CONCLUSION}

Treating family members or relatives creates a personal, emotional, unethical, non-professional relationship that is detrimental to multiple facets of medical services. Treatment of a family member, or self treatment, also prevents the family member (or the physician) from developing a good relationship with his or her own physician. In several developed countries, their medical code of ethics advise physicians to refrain from self treatment, and from treating family members and relatives except in emergency condition or for minor 
illnesses. Learning from the experience of developed countries and adjusting to the changing dynamics of current medical practice of Nepal Medical Council in association with Nepal Medical Association should also revise ethical guidelines for physicians practicing

\section{REFERENCES}

1. Fromme EK, Farber NJ, Babbott SF, Pickett ME, Beasley BW. What do you do when your loved one is ill? The line between physician and family member. Ann Intern Med. 2008;149(11):825-31. Epub 2008/12/03. PubMed PMID: 19047031.

2. Latessa R, Ray L. Should you treat yourself, family or friends? Fam Pract Manag. 2005;12(3):41-4. PubMed PMID: 15813304.

3. Guille C, Sen S. Prescription drug use and selfprescription among training physicians. Arch Intern Med. 2012;172(4):371-2. Epub 2012/03/01. doi: 10.1001/archinternmed.2011.791. PubMed PMID: 22371930; PubMed Central PMCID: PMCPmc3654840.

4. Krall EJ. Doctors who doctor self, family, and colleagues. World Med J. 2008;107(6):279-84. PubMed PMID: 18935895.

5. La Puma J, Stocking CB, La Voie D, Darling CA. When physicians treat members of their own families. Practices in a community hospital. N Engl J Med. 1991;325(18):1290-4. doi: 10.1056/ NEJM199110313251806. PubMed PMID: 1922224.

6. Dusdieker LB, Murph JR, Murph WE, Dungy Cl. Physicians treating their own children. Am J Dis Child. 1993;147(2):146-9. PubMed PMID: 8427235. in Nepal which should give clear advice regarding physicians treating themselves or their relatives.

\section{CONFLICT OF INTEREST}

None

7. Chen FM, Feudtner C, Rhodes LA, Green LA. Role conflicts of physicians and their family members: rules but no rulebook. West J Med. 2001;175(4):2369; discussion 40. PubMed PMID: 11577049; PubMed Central PMCID: PMC1071568.

8. Mailhot M. Caring for our own families. Can Fam Physician. 2002;48:546-7, 50-2. PubMed PMID: 11935719; PubMed Central PMCID: PMC2214008.

9. Bioethics Co. Pediatrician-Family-Patient Relationships: Managing the Boundaries. Pediatrics. 2009;124(6):1685-8. doi: 10.1542/peds.2009-2147.

10. Eastwood GL. When relatives and friends ask physicians for medical advice: ethical, legal, and practical considerations. J Gen Intern Med. 2009;24(12):1333-5. doi: 10.1007/s11606-009-11271. PubMed PMID: 19784705; PubMed Central PMCID: PMC2787942.

11. American Medical Association. Council on Ethical and Judicial Affairs. Code of Medical Ethics Opinion E-8.19: Self-treatment or Treatment of Immediate Family Members [Internet]. 1993 [cited 2013 Jun 26]. Available from: http://www.ama-assn.org/ama/pub/ physician-resources/medical-ethics/code-medicalethics/opinion819.

12. General Medical Council. Treating Family Member. Good Medical Practice [Internet]. 2013 [cited 2013 Jun 26]. Available from: http://www.gmc-uk.org/ guidance/10247.asp. 